\title{
A nation of people called patients
}

\author{
William G Pickering Newcastle upon Tyne
}

\section{Author's abstract}

The implications of the casual and ubiquitous use, by doctors health-workers and politicians, of the word 'patient' are here discussed. Given that the many implications of this noun do not include health or normality (rather the contrary), it is questionable who, if anyone, profits from its indiscriminate use - and its use, even, at all.

A patient, according to the dictionary, is a person under medical treatment. The National Health Service (NHS), however, takes an altogether different view by baptising all persons on general practitioners' lists everyone in a contractual relationship with a doctor with the label of 'patient'. No matter that a greater proportion of such persons are in the rudest of health; medicine's quaint vernacular insists that they are all patients - virtually the entire population!

This misnomer has helped produce an imprecise and unsalubrious mood which is endemic. Antenatal clinics book and supervise 'patients', as though pregnancy was an illness. 'Patients' paradoxically attend well-woman clinics. Politicians speak of 'doctors enlarging their lists of patients', and of 'patients' (ie, normal healthy people) 'attending surgeries for health checks'. Be its use habit or design, the indiscriminate appellation is guilty of much innuendo, such as difference, ill-health, submission and dependency - the effects of which not only rather set the tone for consultations but spread far beyond the surgery or hospital into everyday life. Just whom the word 'patient' benefits is a moot point (doctors? the well person? the sick person?), but what it does do is unnecessarily dispel that most happy consideration normality, which, if once uprooted from its owner can prove exceedingly difficult to re-implant. Must the NHS use a word so redolent of sickness to identify those people it is available to serve? Does the word, in no small part, acting like a self-fulfilling prophecy, account for the NHS's increasing inundation? Would calling the healthy and perhaps even the unhealthy, clients or people (lest anyone should forget) not be a

\section{Key words}

Patients; person; implications; normality; health. healthier and less confusing starting point for the population, its doctors and the service itself?

There is no convincing evidence that any person, ill or well, benefits from the custom of being known as a patient. There are those, however, who perceive the word as valuable in prompting special medical attitudes from medical personnel, particularly towards those who are sick. This view unsettlingly presumes that it is possible for the instinct of these personnel to be actually smothered (rather than honed) by medical training such that their charges, even when illness is self-evident, have to be identified by the label 'patient' before suitable medical attitudes are switched on. By the by, is it possible that unhelpful medical attitudes are simultaneously switched on - condescension and servility for example? But further important aspects and implications of the descriptive noun 'patient' pertain not exclusively to the attitudes of the labellers, but also to the attitudes of those labelled.

It is true that some people remain unmoved howsoever they are designated. The 25 -year-old man telephoning for an appointment for immunisation prior to foreign travel is probably quite indifferent when the receptionist asks 'are you a patient at this surgery?'. But what of people with, say, diabetes, hypertension or asthma, who elect not to convert their condition into an illness, and who aim to separate it from normal life as little as is possible? 'Patient' is an irksome reminder of how others see them, jarring uncomfortably with how they see themselves. Conversely, there is another (by no means uncommon) species of person who seize with rapture the opportunity of becoming 'a patient'. They graft themselves to its connotations, conform to its suggestions and with it, buttress their presumed or desired invalidity. The medicalising word, especially if underlined with a medication, investigation or referral can, most effectively, coax and even confirm neuroticism. Would a person or client or panelmember or customer be able to develop the manners and mentality of an invalid with the ease that a 'patient' can?

Ilingworth's invaluable book, The Normal Child (1), contains a collection of problems commonly brought by mothers to doctors. His explanations have made tranquil many a mother (and doctor) by 
demedicalising numerous supposed abnormalities, classifying them all as NORMAL variations. The book's title hints that Ilingworth had seen too many children find their way into the maw of medicine unnecessarily, disruption and anxiety being attendant until reassurance was finally found. A tome of equivalent purpose, The Normal Adult, awaits authorship. Such is the fashion for earnestly applying a medical label to every facet of human behaviour and complaint - then coupling 'patient' thereto - that the book is likely to remain unwritten for the time being.

Notwithstanding, there is a powerful medical case for deliberately investing sickness with an air of normality, and also ensuring that health is not blighted with an air of sickness. What greater disservice than to discharge people from a consultation who have either no medical condition or one which is simply managed, and for them to depart believing that they are ill? Far better to maintain that all medical problems, supposed, real, trivial and major, are unwelcome intrusions upon and not certain extinguishers of, health and normality; and gently to clarify that illness, even the gravest, does not invariably corrupt its victim into something other than a person.

This is not to propose that every illness be belittled by hearty assertion of there being 'nothing wrong really'. Just as a named diagnosis can afford immeasurable relief to a person, much comfort follows the doctor's avowal, when appropriate, that there is indeed medical need - and that it will be met. But it must continually be borne in mind that whilst a disease is one thing, a diseased relationship with normality is quite another; one whose occurrence or avoidance is very often more definitively under the direction of the doctor than the disease itself. Recovery from illness, accommodation of illness, reassurance of minor disease being just that, and maintenance of health, are all contingent upon $\stackrel{f}{?}$ preservation of feelings of normality. Although this is a matter of at least equal importance to pure medical input (and perhaps the most subtle aspect of the $\frac{\rho}{5}$ doctor's job) it is often neglected in favour of bleak $\stackrel{\mathbb{Q}}{\complement}$ medical jargon. To call this a 'professional approach' ڤ would be a liberal euphemism; it is a narrow approach, $\vec{\circ}$ which reference to people or clients rather than patients may help redress.

Medical workers will conjecture that 'doctor-client' relationships might make people less tractable. The term has the ring of equality, with no overtones of teacher-pupil or patron-suppliant. They need not fret. Diagnoses would be more simply unravelled and 6 management made smoother if people felt less $\vec{\theta}$ obligated distractingly to assume a sick role. Less $\frac{}{工}$ obligation too for the doctor to deliver pacifying tokens - 'patient' being a prescriptive as well as descriptive noun! Above all, floating inexorably across each $\overparen{D}$ consultation, from the very start, is the scent of $\vec{\oplus}$ normality which, though delicate (and all too easily overpowered by the medicalising aroma of 'patient'), when present, weakens and deters disease as surely as it invigorates human constitution.

William $G$ Pickering $M B, B S, M R C P, D C H$, DRCOG, AFOM, General Practitioner, 7 Moor Place, Gosforth, Newcastle-upon-Tyne, NE3 4AL.

\section{Reference}

(1) Ilingworth R. The normal child. London: Churchill Livingstone, 1986. 